\title{
Model-based Development of a Holistic Thermal Management System for an Electric Car with a High Temperature Fuel Cell Range Extender
}

\author{
Dipl.-Ing. Torben Fischer ${ }^{1}$ Dipl.-Ing. Florian Götz ${ }^{1}$ \\ Dr.-Ing. Lars Fredrik Berg ${ }^{1}$ Dr.-Ing. Hans-Peter Kollmeier ${ }^{1}$ Prof. Dr. rer. nat. Frank Gauterin ${ }^{2}$ \\ ${ }^{1}$ Fraunhofer Institute for Chemical Technology (ICT), Project Group New Drive Systems, Germany \\ \{torben.fischer, florian.goetz, larsfredrik.berg, hans- \\ peter.kollmeier\} @ict.fraunhofer.de \\ ${ }^{2}$ Institute of Vehicle System Technology, KIT, Germany, frank.gauterinafast. kit. edu
}

\begin{abstract}
Within the Fraunhofer innovation cluster "Regional Eco Mobility 2030" (REM2030) concept developments to improve the energy efficiency of regional eco mobility of the future are investigated. An AUDI A1 Sportback is used as a technology demonstrator with an entirely electric powertrain, completed to a serial hybrid by a fuel cell range extender. A methanol reformer provides hydrogen for the high temperature fuel cell. The main focus of this paper is the thermal management system of the car, which has to deal with different temperature levels and must be designed for zero emissions and energy efficiency. The model-based development of such a system using Modelica is described, comprising a conception, simulation and testing phase.
\end{abstract}

Keywords: REM2030; Thermal Management; Modelica; Electric Vehicle; Serial Hybrid; Heat Pump

\section{Introduction and State of the Art}

In conventional automobiles with combustion engines, waste heat is used to heat the passenger cabin. Electric cars do not dispose of sufficient waste heat to cover all caloric demands. Furthermore, additional components have a more sensitive operating temperature and require thermal conditioning. The thermal management system of the vehicle must therefore provide sufficient cooling and heating power. The range of an electric car is already limited due to the low energy density of the traction battery compared to conventional combustion fuels, and these thermal restrictions can cause a further range reduction. Using Modelica, a holistic thermal management system for an electric car, equipped with a high temperature fuel cell range extender, is developed. The goal is to minimize the electric energy demand of the thermal management system by using all heat sources and sinks in a holistic approach. In a further step the concept and the simulation will be validated on the basis of hardware testing. Once the functionality of the system is proven, additional research will be dedicated to the operational strategy of the vehicle.

Thermal management systems for electrified powertrains can generally be classified according to the type of the battery cooling method and the heating technology applied. Battery electric vehicles often have a high-voltage PTC (positive temperature coefficient) heater to generate the demanded amount of heat (for example Tesla Model S, Smart Electric Drive and VW e-up). However, there are a number of vehicles which are optionally equipped with heat pumps instead of PTC heaters, like the VW e-Golf and the BMW I3. In the case of the Nissan Leaf II and Renault Zoe the heat pump is already integrated in series-production vehicles. The cooling media used to cool the battey are air, liquid and refrigerants, with refrigerants providing the highest efficiency but also showing the highest complexity. To the best of our knowledge, heat pumps as part of a holistic thermal management system are not yet commercially available, and are still the subject of research, for example in Germany within the projects GATE ("Ganzheitliches Thermomanagement im E-Fahrzeug") and EFA 2014/2 ("Energieeffizientes Fahren 2014 Phase 2").

\section{Conception Phase}

To develop a thermal management system, the system and its components must first be analyzed in terms of their nominal heat in- and output and their optimal thermal operating ranges.

\subsection{System Description}

In contrast to a conventional vehicle, the powertrain of an electric car includes the following components:

- Traction battery

- Power electronics

- Electric traction motor 
The demonstrator vehicle of REM2030 is equipped with a $13 \mathrm{kWh}$ Li-ion battery, assembled with 84 serial and two parallel cells. The traction motor is a permanently excited synchronous motor (PSM) and has a peak power of $80 \mathrm{~kW}$, while the continuous power is at $50 \mathrm{~kW}$.

The electrical range without accessory devices is projected to be about $80 \mathrm{~km}$, which can be increased by a range extender. The range extender is realized by a high temperature fuel cell with a methanol reformer (RMFC) providing an electrical power output of $5 \mathrm{~kW}$ (cf. Berg, 2015). With a tank volume of 11 liters, the range can be approximately doubled. The power electronics includes three DC/DC converters: a buck converter, which converts the intermediate circuit voltage $(400 \mathrm{~V})$ to the onboard power supply $(12 \mathrm{~V})$ and two boost converters, which convert the fuel cell voltage $(150 \mathrm{~V})$ to the intermediate circuit voltage or the battery voltage $(250 \mathrm{~V}-350 \mathrm{~V})$ to the intermediate circuit voltage $(400 \mathrm{~V})$. Finally, an inverter is installed to deliver AC voltage to the PSM depending on the requested torque and speed. This inverter can also be used to convert the AC charging current.

\subsection{Heat Sources and Sinks}

The operation temperatures of the components vary significantly, so they can act both as a heat source and a heat sink, depending on the ambient conditions. Additionally, the passenger cabin plays a major role in the thermal management system. Table 1 shows the identified heat sources and sinks within the system borders.

\begin{tabular}{|l|l|l|}
\hline Component & $\begin{array}{l}\text { Operating } \\
\text { Temperature }\end{array}$ & $\begin{array}{l}\text { Peak Heat } \\
\text { Flow Rate }\end{array}$ \\
\hline Battery & $20-40^{\circ} \mathrm{C}$ & $6 \mathrm{~kW}$ \\
\hline Fuel Cell & $140-180^{\circ} \mathrm{C}$ & $5 \mathrm{~kW}$ \\
\hline Cabin & $20-25^{\circ} \mathrm{C}$ & $-3 . .6 \mathrm{~kW}$ \\
\hline $\begin{array}{l}\text { Power } \\
\text { Electronics }\end{array}$ & $\mathrm{Up}$ to $150^{\circ} \mathrm{C}$ & $5 \mathrm{~kW}$ \\
\hline Electric Motor & $\mathrm{Up}$ to $130^{\circ} \mathrm{C}$ & $3 \mathrm{~kW}$ \\
\hline Sun &. & $1.5 \mathrm{~kW}$ \\
\hline
\end{tabular}

Table 1. Heat sources and sinks in an electrical vehicle

\subsection{Efficient Heating and Cooling Concept}

To achieve the defined goal it is necessary to use all heat sources to cover the heat demands. The residual heat demand must be covered at the expense of range, because the electrical energy of the traction battery is used. One promising approach to minimize electrical consumption for heat generation is to integrate ambient heat by using a heat pump. Cooling demands must also be covered using all the heat sinks. Usually, the ambient air acts as a heat sink, but the temperature range of the battery and the cabin can be below the ambient temperature in some scenarios. An active cooling method must therefore be implemented. Conventionally, an AC-system is used, which can be achieved by a flow reversal in the heat pump. This is the state-of-the-art in reversible split air-conditioning units (Hundy et al., 2008).

Figure 1 shows the concept consisting of a heat pump with flow reversal, which is called a "thermal module", and the connected periphery. The blue part on the right is the inner coolant circuit connected to the cabin heat exchanger, and the blue part on the left is the outer coolant circuit connected to the ambient heat exchanger. There are multiple operating possibilities of the thermal management system, which can be classified depending on the season. In the winter scenario the ambient temperature drops below the set temperature of the passenger cabin. If the range extender is running, the entire heat demand should be covered by the waste heat of the fuel cell. In extreme scenarios, the remaining heat demand can be covered by the heat pump. Waste heat from electric components will be released into the environment. In cases where the range extender is not running, the heat pump is turned on, while the waste heat of electric components is used as an additional heat source for the heat pump.

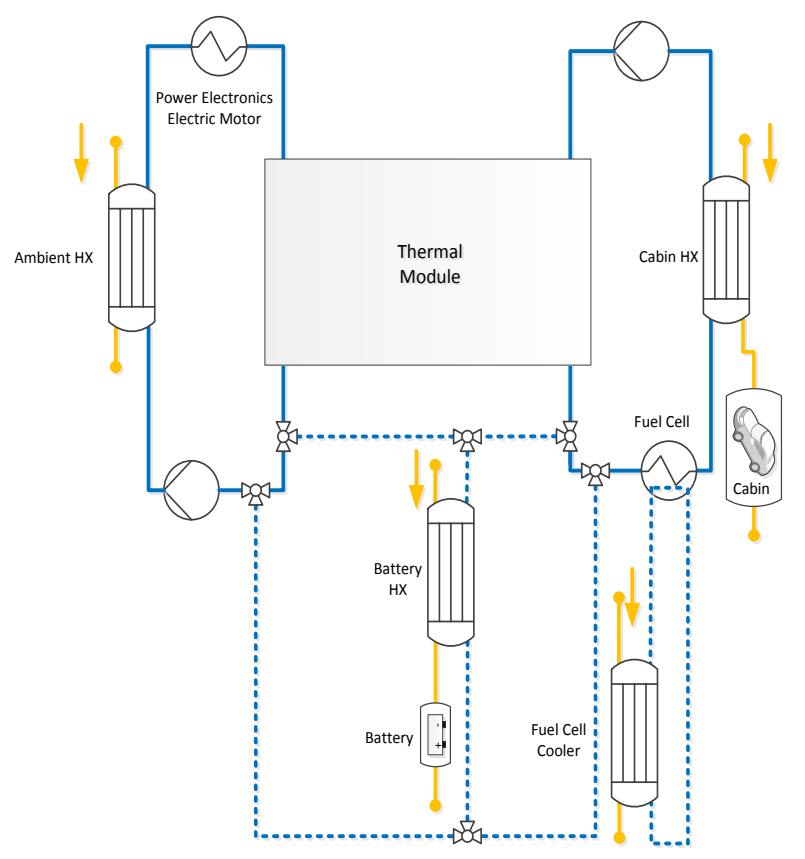

Figure 1. Thermal Management System

The summer scenario represents ambient temperatures above the passenger cabin set temperature. Waste heat from the electric components will be released to the environment, together with excessive heat from the cabin. The fuel cell has its own heat exchanger allowing the waste heat to be transferred into the 
environment. The refrigeration process provides cooling energy to cool both the cabin and the battery.

In the transition phase the ambient temperature is considered to be slightly below the set temperature. This leads to two cases: Either there is too much waste heat from the fuel cell, which has to be partially released into the environment, or the range extender is not active, so that the heat pump has to overcome the remaining temperature difference.

The battery is air-cooled and can be connected to the coolant circuits via the battery heat exchanger. Since the battery needs to be heated and cooled, three-wayvalves are installed, which allow the battery to be connected to the respective coolant circuit. The battery conditioning is therefore independent from the cabin air conditioning. This function could be necessary for example during a high demand phase on a cold winter day, when the battery has to be cooled while the cabin has to be heated.

\section{Simulation Phase}

To verify the function of the concept, a simulation model of the system was developed. Further potential for optimization might also be identified by running simulations, notably by carrying out a sensitivity analysis to identify the most significant parameters.

The models were built up in Modelica using the Dymola environment, based on the TIL Suite Library (Richter, 2008) by TLK Thermo GmbH and the Powertrain Library (Schweiger, 2005) by DLR. Thermodynamic fluid data are drawn from TILMedia and Refprop.

\subsection{Thermal Module Model}

The thermal module consists of two plate heat exchangers, two fixed orifice valves, a compressor, a four-way-valve and an accumulator. The heat exchangers change their function depending on the flow direction.

The plate heat exchanger model is based on a finitevolume-method and discretizes the flow path into three cells which each fulfill the energy and mass balance equations. Pressure drops within the heat exchangers are not taken into account. Heat transfer coefficients for the coolant side are based on the correlation for plate heat exchangers by the VDI (Martin, 2010), while the heat transfer coefficients for the refrigerant side are estimated on the basis of the Shah and Chen correlations (Shah, 1979 and Chen, 1966). The circuit runs on the refrigerant R1234yf, whose thermodynamic data are drawn from Refprop.

The 4-way-valve allows the flow direction to be adjusted, which is relevant for the initialization of the pressure states. The control of the valve is driven by the sign of the difference between ambient temperature and set temperature in the passenger cabin. The initialization of the refrigeration system therefore depends directly on the ambient temperature. The receiver is placed on the low pressure side before the compressor, which is fixed in the flow reversal system. An inner heat exchanger, which is modeled by two tubes with a heat transport, ensures the best possible energy use.

\subsection{Thermal Management Model}

The thermal module is extended by two secondary coolant circuits, which release or receive heat from the connected components. The coolant flows through the converters and the electric motor, and they are modeled as tubes whose thermal input is calculated by the appropriate models in the complete vehicle system (see 3.4). The battery, fuel cell and passenger cabin are connected to the coolant circuits via fin and tube heat exchangers with a discretization of three cells. This is mainly due to a change in the heat transport medium from liquid to gas. The passenger cabin is modeled as a simple homogenous volume with a heat transfer to the surround environment. An air recirculation is implemented to quantify potential energy savings.

\subsection{Battery Model}

The battery is an important part of the thermal management system, as its temperature increases depending on the inner resistance and the current. The inner resistance, in turn, depends mainly on the temperature and the state of charge. The battery model therefore needs to include a feedback between electric output and thermal output, which influence each other.

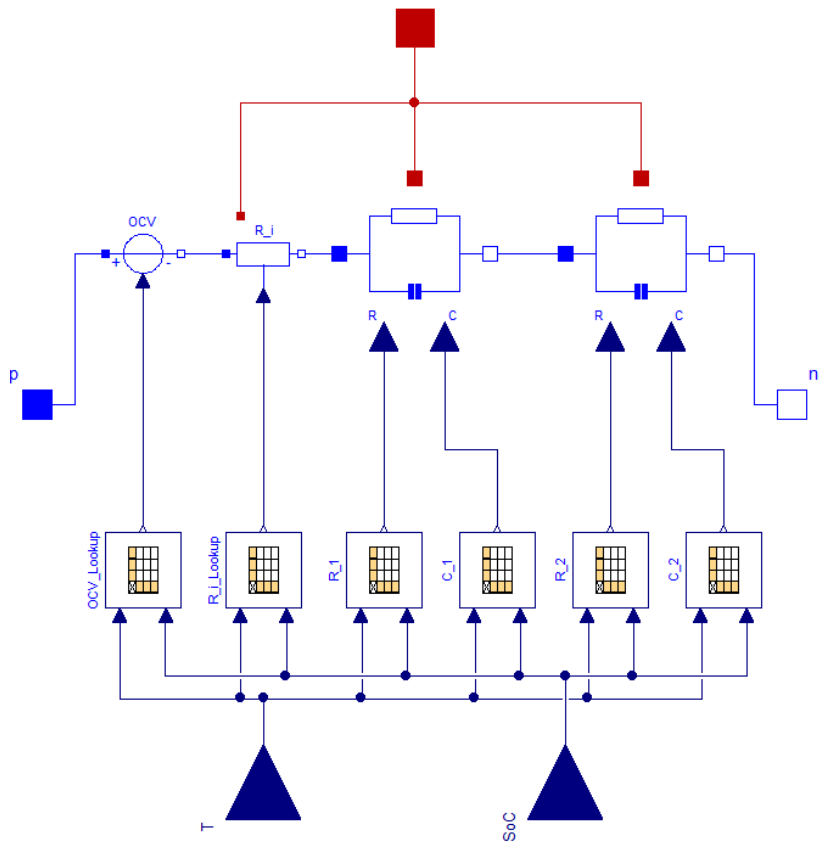

Figure 2. Equivalent circuit model with two RC elements

To develop a realistic, fast-running model, which should be used within a system simulation, an equivalent circuit diagram with an inner resistance and two RC elements was modeled. This method is widely 
known and can be also found in the literature (Andre et al, 2010).

Battery cycling tests deliver parameter values for the inner resistance, and $\mathrm{R} 1 / \mathrm{C} 1$ or $\mathrm{R} 2 / \mathrm{C} 2$ for the $\mathrm{RC}$ elements at an open circuit voltage. These tests are performed within a climate chamber and cells are (dis-) charged with a given current, varying frequency, varying temperature and varying state of charge. Electrical impedance spectroscopy is applied to determine the battery parameters. A caloric measurement of the cell in a waterbath determines the specific heat capacity, which is needed to calculate the temperature of the battery.

The complete parametrized model has an electricthermal feedback, in which the battery is modeled as a thermal mass and one cell is scaled to a whole battery pack.

Using the object-oriented capacities of Modelica, it is possible to instantiate one battery cell several times to build up a battery pack consisting of individual cells. This provides a good possibility to investigate cooling concepts on a component level, since the individual temperature of each cell can be calculated. However, this significantly increases the computation time, and is therefore not taken into account.

\subsection{Complete Vehicle Model}

The results from the thermal management system simulation show the total energy consumption of the compressor and the pumps. To evaluate the effect on the range, a complete vehicle simulation with longitudinal dynamics must be performed. The complete vehicle model is based on the Powertrain Library calibrated with our vehicle and component parameters, complemented by the battery and motor models developed.

An interface between the thermal management model and the vehicle model has been created, which encompasses the following considerations:

- Effects of the thermal management system on the battery temperature

- Influence of the electrical power input of the compressor on the state of charge (SOC) of the traction battery

- Heat dissipation of converters and motor

The map-based model of the electric motor provides a torque depending on the position of the accelerator pedal and the actual speed. The supplied torque is needed to overcome the driving resistance at constant speed. A surplus of torque results in increasing speed and thus in the higher velocity of the car. The motor model also delivers the efficiency rate at the actual operating point, which is used to calculate the amount of heat transferred into the coolant system.

To quantify the benefit of the thermal management system in terms of range and consumption, the WLTP cycle (Worldwide harmonized Light vehicles Test Procedures) is chosen as a reference driving cycle.

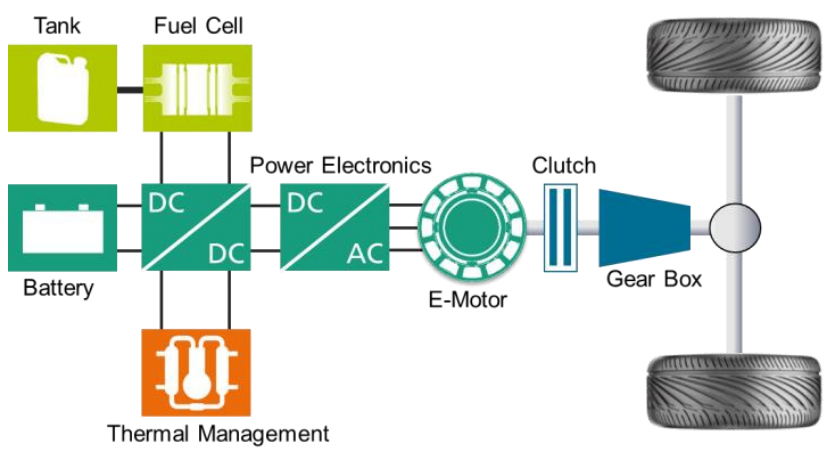

Figure 3. Complete vehicle system with electrical, mechanical or hydraulic connections

\subsection{Simulation Setup}

All simulations are carried out with the base vehicle outlined in the system description 2.1. The cabin volume is assumed to be $2.5 \mathrm{~m}^{3}$, the overall heat coefficient of the cabin to the surrounding environment is defined to $40 \mathrm{~W} / \mathrm{K}$ according to measurements. The total window area is $2.8 \mathrm{~m}^{2}$ and the frontal area is 2.04 $\mathrm{m}^{2}$ with a drag coefficient of 0.33 . The mass of the vehicle is defined to be $1200 \mathrm{~kg}$ with a rolling resistance coefficient of 0.014 .

\section{Control System}

\subsection{Classic Control Approach}

The thermal management system consists of several components, which must be maintained within their thermal operating range. This is either for comfort reasons, as in the case of the passenger cabin, or for life time and performance reasons, in the case of the battery and the fuel cell.

Relating to our system there are three set temperatures for different components:

- Passenger cabin $\left(\sim 22^{\circ} \mathrm{C}\right)$

- $\quad$ Fuel cell $\left(\sim 160^{\circ} \mathrm{C}\right)$

- Traction battery $\left(\sim 20-40^{\circ} \mathrm{C}\right)$

In this multiple-input and multiple-output system (MIMO) every input influences more than one output. To apply a classic control approach it is therefore necessary to decouple the systems and to treat each partial system as a system with a single input and a single output (SISO). As stated in (Levine, 1999) it can be difficult or impossible to find a controller for a MIMO system, such that every input affects only one output. In this case, the compressor speed is controlled by the temperature in the passenger cabin, while the three-way-valve in the inner coolant loop is controlled by the battery temperature. If the battery needs to be cooled down, the 3-way-valve opens, which causes a temporary reduction of cooling power for the cabin. 
The temperature change in the cabin eventually increases the compressor speed. So the control variable of the 3-way-valve influences both the battery and cabin temperature, but is still a simple approach to control this MIMO system.

However, this kind of control system always produces some overshoots, leading to an inefficient way of providing heating and cooling energy. Furthermore, the temperature change in the cabin might cause a feeling of discomfort for the passenger, which has to be avoided.

\subsection{Dynamic Optimization}

Another approach is to treat the whole thermal management system as a MIMO system. A cost function will be defined which includes the parameters to be minimized. As described in (Gräber et al, 2009), the system will be repeatedly solved online in an optimization loop, while the optimization algorithm changes the set of parameters and eventually keeps those resulting in a minimized cost function. This step is repeated in every given sample time for a given time horizon.

The computational time can be very costly, but since thermal systems react rather slowly, the sample time can be increased. This can lead to a more efficient control system, as overshoots can be avoided. Furthermore, it can be extended to a predictive control, which could eventually include data from a predictive operational strategy of the range extender.

The model developed can be used in its basic form to control the system using a dynamic optimization, although it has to be adapted when using gradientbased optimization algorithms. Look-up tables and fluid property models are particularly affected.

\section{Preliminary Results}

\subsection{PTC vs. holistic approach with heat pump}

First, the base car equipped with a state-of-the-art PTC heating element is compared to the base car with a heat pump system. The heating element is assumed to completely convert its electric energy to heat.

The results shown in figure 4 were simulated with an ambient temperature of $0^{\circ} \mathrm{C}$, which is also the initial temperature of the cabin. The total consumption within the WLTP cycle and under the mentioned assumptions can be reduced from $18.3 \mathrm{kwh} / 100 \mathrm{~km}$ to 14.3 $\mathrm{kwh} / 100 \mathrm{~km}$, i.e. a decrease of about $22 \%$.

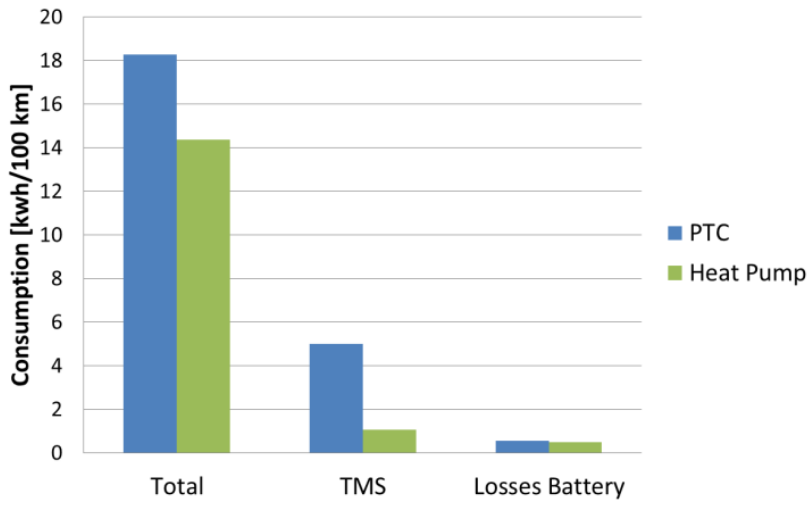

Figure 4. Comparison of the consumption of a conventional PTC heating element and a heat pump system at an ambient temperature of $0^{\circ} \mathrm{C}$

Meanwhile, the electrical range can be increased from 60 to $75 \mathrm{~km}$. The coefficient of performance $(\mathrm{COP})$, which is the coefficient between the thermal output and electrical input of the heat pump, is around 4.5. Pressure drops are not yet taken into account, as stated in 3.1. The battery cooling is not yet active, because its temperature rises from the initial temperature of $0^{\circ} \mathrm{C}$ to a maximum of only about $20^{\circ} \mathrm{C}$ by the end of the range.

\subsection{Annual average advantage}

Assuming that the air conditioning function of the thermal module provides a similar efficiency to that of a conventional air conditioning system, there will be neither an efficiency decrease nor an increase in the summer.

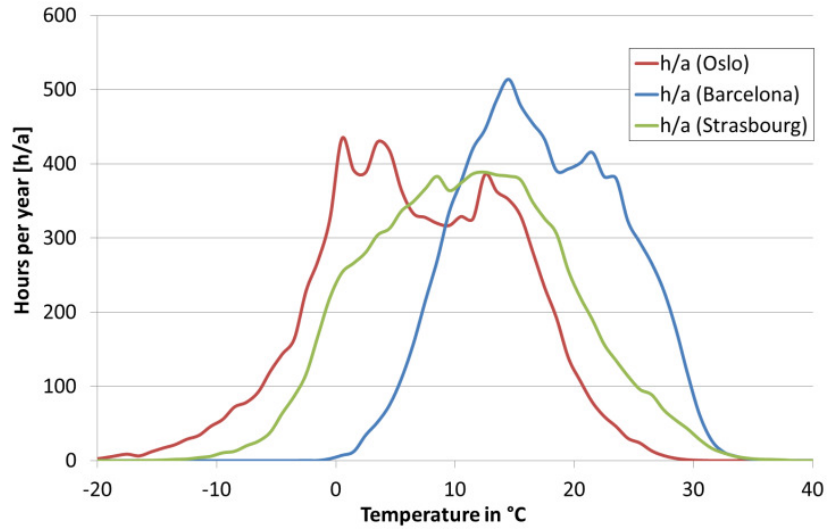

Figure 5. Average temperature profiles in different European cities (VDI 4710 Part 4 March 2014, Table B62, B99, B23 reproduced with the permission of the Verein Deutscher Ingenieure e.V.)

To calculate the annual average advantage of the developed thermal management system, the advantage as a function of the ambient temperature was determined. Using the VDI Norm 4710 (cf. Figure 5), which provides annual statistical meteorological data for European cities, it is possible to weight the 
respective advantage according to the average annual amount of time during which it applies.

The results are shown in table 2, not taking into account any user behavior during different seasons or times of day.

\begin{tabular}{|l|l|}
\hline City & $\begin{array}{l}\text { Annual average } \\
\text { consumption decrease }\end{array}$ \\
\hline Oslo & $15 \%$ \\
\hline Strasbourg & $12.4 \%$ \\
\hline Barcelona & $8.4 \%$ \\
\hline
\end{tabular}

Table 2. Annual average consumption decrease using a holistic thermal management system rather than conventional electric heating

\subsection{Extending Range with a High Temperature Fuel Cell}

The methanol tank capacity is 11 liters, which equates to approximately $11 \mathrm{kWh}$ of additional electric energy.

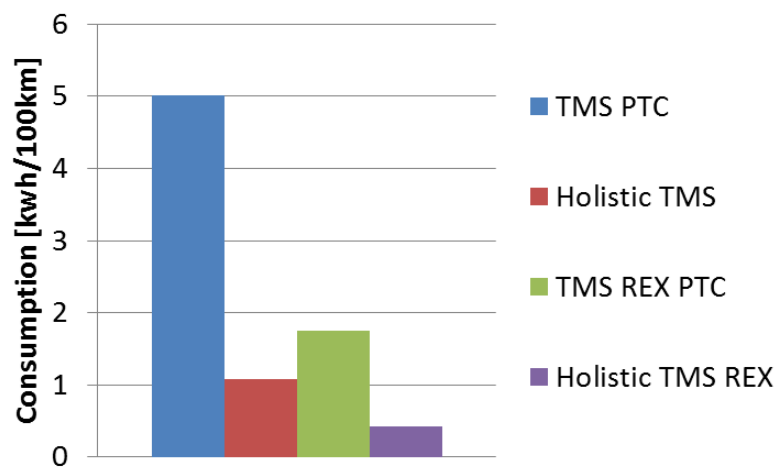

Figure 6. Comparison of the consumption of a conventional PTC heating element and a heat pump system at an ambient temperature of $0^{\circ} \mathrm{C}$

With reference to the results of 5.1 the range can be extended to $143 \mathrm{~km}$ with a conventional heating element and to $153 \mathrm{~km}$ with the holistic thermal management system based on a heat pump. Here there is only a $7 \%$ advantage, because in both cases we use the waste heat of the fuel cell to heat the cabin: no additional heat has to be generated. Figure 6 illustrates this behavior. The average consumption of the thermal management system drops from about $5 \mathrm{kWh} / 100 \mathrm{~km}$ to $1.7 \mathrm{kWh} / 100 \mathrm{~km}$ when using a PTC element. By using a heat pump system this drop is from 1.1 to 0.4 $\mathrm{kWh} / 100 \mathrm{~km}$.

\subsection{Preconditioning Battery}

Another simulative investigation concerned the use of the preconditioning of a battery, which can be energyintensive due to the high thermal mass of the battery. Since the battery's inner resistance is higher at low temperatures, it will heat up itself on sufficient power demand. However, power output is limited at low temperatures, which might result in lower acceleration and also lower maximum velocity of the vehicle. Another issue is so-called lithium plating: the deposition of lithium on the anode as explained in (Korthauer, 2013). This leads to irreversible damage and occurs when charging the battery below $0^{\circ} \mathrm{C}$.

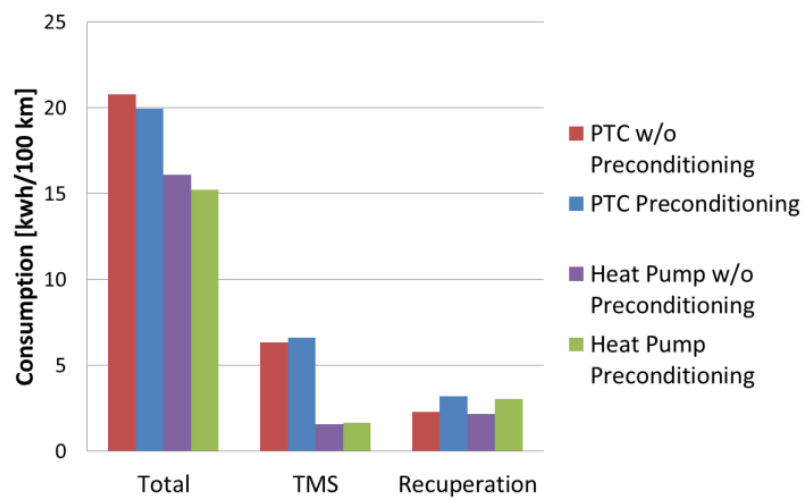

Figure 7. Comparison of consumption of a conventional PTC heating element and a heat pump system at an ambient temperature of $-5^{\circ} \mathrm{C}$

Taking this restriction into account by disabling the regenerative brake at temperatures below $0^{\circ} \mathrm{C}$ shows that preconditioning can decrease the total consumption. Figure 7 shows the simulation outputs with an ambient temperature of $-5^{\circ} \mathrm{C}$ : Using a thermal management system with a PTC heating element, the total consumption can be decreased by about $4 \%$ by preconditioning the battery. While the amount of consumption of the thermal management system rises, the amount of recuperated energy rises more. The same effect can be observed using a heat pump system to precondition the battery, which leads to a decrease of the total consumption by nearly $6 \%$.

\section{Test Bench / Validation}

A test bench for the heat pump has been developed and constructed to establish a validated, lossy model of the system including real heat transfers and pressure drops. The inner and outer coolant circuit can be thermally conditioned, allowing measurement at stationary temperatures. Several realistic scenarios, such as winter or summer conditions, can then be reproduced. The measurement includes temperature, pressure, mass flows and power signals while varying the compressor speed in different reproduced scenarios. This allows adaptation of the simulation model.

A dSpace system is used as a central control unit, which also has the opportunity to extend the test bench to a hardware-in-the-loop test bench. When testing the thermal management system, electric components such as motor and power electronics can be replaced by models, which calculate the output heat depending on 
the driving cycle. Controlled heating elements then physically provide the calculated amount of heat.

\section{Conclusion and Outlook}

Modelica and the environment Dymola are powerful tools to support the development process in the early stage. With the help of these simulations, the potential advantages of the thermal management system for electric vehicles have been shown and the concept verified. A test bench has been constructed to adapt the simulation model of the refrigerant cycle to pressure drops and realistic heat transfer. The model-based development of the thermal management system eventually leads to the buildup in hardware, which will be connected to the components of the powertrain within the demonstrator. The model of the system can also be used to develop an advanced control system using dynamic optimization, which will replace the existing classical control approach. The functional mock-up interface (FMI), providing a simple possibility to exchange models between supported CAE-software, will play a major role within this undertaking. Finally, with a test on a dynamometer the functionality will be certified and the advantages of the systems will be proven.

\section{References}

D. Andre et al, "Characterization of high-power lithium-ion batteries by electrochemical impedance spectroscopy. II:Modelling”, Journal of Power Sources, 2010

L. Berg, "Range Extender mit Methanol-Fuel-Cell", HZwei, Hydrogeit Verlag, April 2015, p.30

J.C. Chen, "A Correlation for Boiling Heat Transfer to Saturated Fluids in Convective Flows", Ind. Eng. Chem. Process Design and Development 5, p. 322, 1966

M. Gräber et al., "Using Functional Mock-up Units for Nonlinear Model Predictive Control", 9th International Modelica Conference, Munich, 2009

G. Hundy et al., "Refrigeration and Air-Conditioning", Butterworth-Heinemann, 2008

A. Jeckel, „Thermische Anforderungen von Hochvoltbatterien in elektrischen Antriebssträngen“, VDI Wissensforum Thermomanagement für elektromotorisch angetriebene PKWs, 2013

R. Korthauer, "Handbuch Lithium-Ionen-Batterien", Springer Vieweg, 2013, p.166

W. Levine, "Control System Fundamentals“, CRC Press, 1999 , p. 166

H. Martin, "Pressure Drop and Heat Transfer in Plate Heat Exchangers", "VDI Heat Atlas", Chapter N6, 2010

C. Richter "Proposal of New Object-Oriented EquationBased Model Libraries for Thermodynamic Systems"

C. Schweiger et al., "The PowerTrain Library: New Concepts and New Fields of Application", 4th International Modelica Conference, Hamburg, 2005
M.M. Shah, "A general correlation for heat transfer during film condensation in pipes", International Journal of Heat and Mass Transfer 22, p.547, 1979

Verein Deutscher Ingenieure, VDI Norm 4710, Part 4 March 2014, Table B62, B99, B23 